\title{
Seven-year survival of renal transplant for oxalate nephropathy due to short-bowel syndrome
}

\author{
H. Kistler, J. Peter, G. Thiel and F. P. Brunner \\ Medizinische Abteilung, Spital Limmattal Schlieren, Zurich and Abteilung für Nephrologie, Departement für Innere \\ Medizin, Universitätsklinik in Basel, Switzerland
}

\section{Introduction}

Patients with ileal resection or extensive jejunal resection resulting in malabsorption are likely to develop renal hyperoxaluria [1-3]. Deficiencies due to malabsorption can be avoided if supplementation therapy is instituted as early as possible, but in patients with extensive bowel resection steatorrhoea cannot be corrected completely. Hyperoxaluria due to hyperabsorption of oxalic acid or its precursors is a well-established phenomenon, leading to renal complications such as recurrent urolithiasis, oxalate nephropathy, and ultimately end-stage renal failure [4-6]. In this report we describe a female patient with a severe malabsorption syndrome and hyperoxaluria after extensive smallbowel resection. Five years after the initial operation the patient suffered from recurrent stone formation and occasional urinary tract infections. The renal function deteriorated continuously and 25 years after the small-bowel resection the patient was in severe uraemia. Six months after starting maintenance haemodialysis the patient received a cadaveric kidney transplant. Despite persisting hyperoxaluria during the first 5 years after transplantation the transplant has continued to function normally over a period of 7 years with normalization of urinary oxalate excretion and no further stone formation occurred. To our knowledge this is the first reported case of a long-term successful kidney transplantation in a patient with a short-bowel syndrome and enteric hyperoxaluria.

\section{Case report}

In 1958 at the age of 33 years this female patient underwent surgery for myoma and appendectomy without appendicitis. Three years later, in 1961, an extensive resection of necrotic small bowel was necessary because of unrecognized bowel obstruction. Approximately $90 \mathrm{~cm}$ of small bowel and most of the large bowel remained. Barium passage from

Correspondence and offprint requests to: Prof. Dr H. Kistler, Spital Limmattal, 8952 Schlieren, Switzerland. stomach to caecum was found to take only $15 \mathrm{~min}$. Consequently the patient developed a severe global malabsorption syndrome and a weight loss of $20 \mathrm{~kg}$ in less than 2 years. When the patient was first seen by us she weighed $42 \mathrm{~kg}$, had a height of $162 \mathrm{~cm}$, and suffered from hypocalcaemic tetany, hypokalaemia, and hypomagnesaemia.

The following laboratory results were obtained (with normal values in brackets): Faecal fat $50 \mathrm{~g} / 24 \mathrm{~h}$ $(<7 \mathrm{~g} / 24 \mathrm{~h})$, faecal nitrogen $4.7 \mathrm{~g} /$ day $(<2 \mathrm{~g} /$ day $)$, xylose absorption $15 \%(20-35 \%)$, vitamin $\mathrm{B}_{12}$ absorption $0.08 \%(>4 \%)$, lactose absorption was highly abnormal, with severe diarrhoea. Blood serum values: albumin $22 \mathrm{~g} / 1(>36 \mathrm{~g} / 1)$, calcium $1.8 \mathrm{mmol} / 1$ (>2.2 $\mathrm{mmol} / \mathrm{l})$, potassium $3.2 \mathrm{mmol} / 1(>3.7 \mathrm{mmol} / \mathrm{l})$ and magnesium $0.6 \mathrm{mmol} / \mathrm{l}(>0.8 \mathrm{mmol} / \mathrm{l})$. Serum creatinine was at the upper limit of normal with $80 \mu \mathrm{mol} / 1$. The patient received dietary counselling with the introduction of a low-fat diet with the addition of mediumchain triglycerides, vitamin supplementation, and oral calcium $1-2 \mathrm{~g} /$ day. On this regime the patient gained $10 \mathrm{~kg}$ in weight, but suffered persistently from an abnormal frequency and consistency of bowel movements despite different drug trials.

Five years after the small-bowel resection the patient passed a first kidney stone. Starting in 1973 the patient suffered from recurrent stone formation on both sides with or without obstruction or infection and Gramnegative septicaemia. At least six times she underwent operations to remove renal calculi. At one time she passed 20 small renal stones within 1 month. The chemical analyses of the stones always revealed a calcium oxalate composition. Urinary excretion of oxalic acid was regularly highly abnormal, above $500 \mu \mathrm{mol} /$ day. Dietary restriction of oxalic acid or various drug trials had no permanent effect on oxalate excretion (Figure 1); the normal values for oxalate excretion in 1977 and 1978 were obtained during hospitalization of the patient. Figure 2 illustrates the progressive deterioration of the kidney function. In 1986 the patient became obliguric, probably following ingestion of a small dose of indomethacin, and developed uraemia, with a serum creatinine of 


\section{$\mu \mathrm{mol} / \mathrm{d}$}

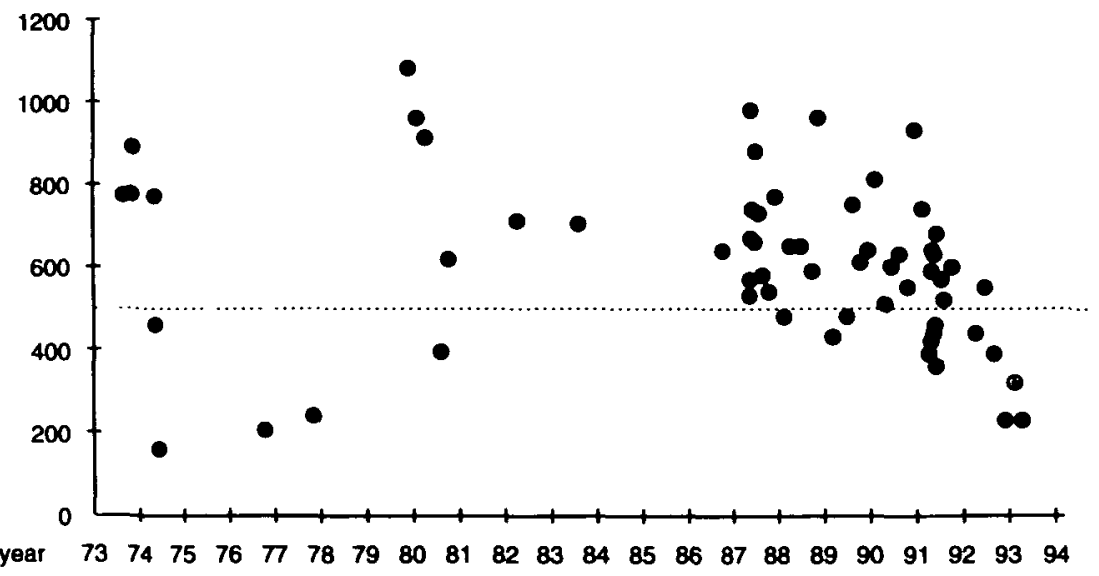

Fig. 1. Renal oxalate excretion (normal value $<500 \mu \mathrm{mol} /$ day).

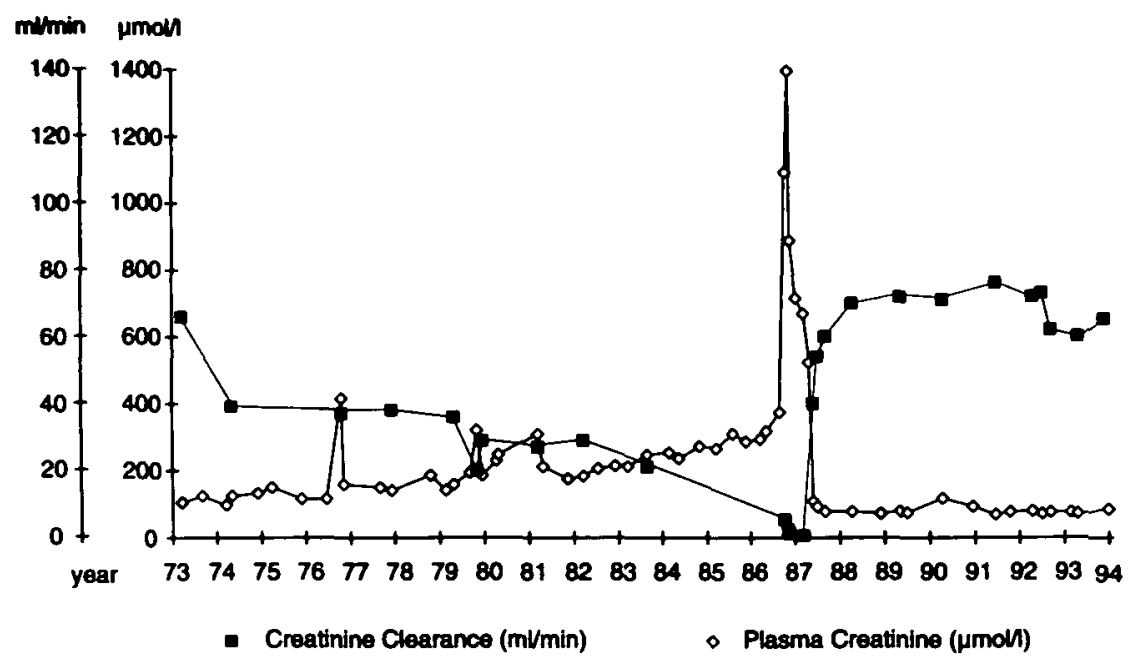

Fig. 2. Plasma creatinine and creatinıne clearance before and after kidney transplantation in 1987.

$1300 \mu \mathrm{mol} / \mathrm{l}$ and acidosis with a $\mathrm{pH}$ of 7.06. No obstruction was seen on ultrasound, but both kidneys were small. Consequently the patient was treated with haemodialysis. Bleeding from the gastrointestinal tract and a decreased left ventricular ejection fraction probably due to oxalate cardiomyopathy were additional severe complications.

Six months later, in February 1987, a cadaveric kidney transplant was performed. Initially the patient was oliguric and a transplant biopsy on day 9 showed ischaemic damage as well as oxalate crystal deposition in the proximal tubular lumina. Despite oxalate crystal deposition, the kidney resumed function on day 12 , when daily haemodialysis was instituted for another 5 days. Thereafter the renal course was uneventful. There was never a sign of rejection despite a HLA-mismatch of five antigens out of a total of six. Seven years after transplantation the plasma creatinine is $70 \mu \mathrm{mol} / \mathrm{l}$ and the creatinine clearance between 60 and $70 \mathrm{ml} / \mathrm{min}$. (Figure 2).

Before transplantation the patient had been tested for her enteral absorption of cyclosporin and prednisone. While prednisone was absorbed normally, wholeblood cyclosporin levels varied between undetectable and barely immunosuppressive concentrations, after oral administration of both twice $100 \mathrm{mg}$ per day of cyclosporin in olive oil as well as $100 \mathrm{mg}$ or $200 \mathrm{mg}$ twice per day dissolved in medium-chain triglycerides. Initial immunosuppression therefore consisted of intravenous cyclosporin $100-200 \mathrm{mg} /$ day for the first 30 days combined with oral azathioprine $100 \mathrm{mg} /$ day and prednisone $20 \mathrm{mg} /$ day. After discontinuing cyclosporin, prednisone was increased to $40 \mathrm{mg} /$ day for 10 days followed by tapering to $10 \mathrm{mg} /$ day over the next 6 months. For the last 6 years the patient has been taking $7.5 \mathrm{mg}$ prednisone and $150 \mathrm{mg}$ azathioprine daily. Complications of immunosuppressive therapy included a localized pulmonary lesion with Cryptococcus neoformans, requiring surgical resection in 1989, and recurrent small skin tumours on the hands and the face.

Regarding oxalate hyperabsorption the patient's 
posttransplant course has been remarkably uneventful. Attempts to reduce oxaluria with dietary restrictions to levels below the upper range of normal $(0.5 \mathrm{mmol} / \mathrm{day})$ were only partially successful. During the first 5 years after transplantation the majority of urinary analyses showed oxalate excretion rates between 0.6 and $0.8 \mathrm{mmol} / \mathrm{day}$ with only occasional values below $0.5 \mathrm{mmol} / \mathrm{day}$. The decrease of oxalate excretion rates to normal values with only occasional results slightly above normal during years 6 and 7 after transplantation is difficult to explain. Oral calcium supplementation was increased to the point where urinary calcium excretion ranged between 3 and $5 \mathrm{mmol} /$ day. Magnesium was supplemented at a dose of $400 \mathrm{mg} /$ day. A trial with organic marine hydrocolloid charged with calcium, although effective regarding control of oxaluria, had to be abandoned because of abdominal distension and constipation. Despite persisting hyperoxaluria during the first few years after transplantation, the patient was rather fortunate not to form a single kidney stone after transplantation. Despite persisting gastrointestinal problems with abdominal distension, fullness, and occasional cramping pains when constipated, this patient has resumed a fully active life as housewife, travelling around the world and enjoying extensive and strenuous walks in the mountains.

\section{Comments}

This is the first report of a long-term survival of a cadaveric renal transplant over a period of 6 years without renal complications in a patient with enteric hyperoxaluria. In the literature we found only one other similar case-report [7]. The patient mentioned in that report developed end-stage renal failure due to renal oxalosis 9 years after extensive bowel resection. Because of difficulties with dialysis procedures he underwent successful renal transplantation with good renal function. The follow-up covered only 10 months and it is not known whether complications developed later in the course. The patient of the present report had a course of 25 years before developing end-stage renal insufficiency. After the transplantation persistent hyperoxaluria with a few exceptions was observed despite various modifications of diet and drugs. No new stone formation or signs of oxalate nephropathy occurred in the graft. The kidney function has remained normal, as reflected by serum creatinine levels below $80 \mu \mathrm{mol} / \mathrm{l}$. Kidney biopsy was not performed to establish potential interstitial oxalate deposits. During the last 2 years urinary oxalate excretion was mostly within the normal range and the risk of recurrence of oxalate lithiasis or oxalate nephropathy is therefore reduced. Despite this uneventful course in our patient we think that the recurrence of oxalosis or stone formation in a renal transplant has to be watched closely.

According to our experience enteric hyperoxaluria should not be a contraindication for renal transplantation $[5,6]$. There are several reports of patients with primary oxalosis and kidney transplantation and good renal function when certain conditions are observed [8-10]. We believe that in secondary hyperoxaluria kidney transplantation should also be considered for patients with end-stage kidney disease in preference to maintenance dialysis. Enteric hyperoxaluria is caused by intestinal hyperabsorption of exogenous oxalic acid and correlates well to the degree of steatorrhoea [11] The reduction of dietary intake of oxalic acid necessary to lower oxaluria into the normal range is nearly impossible to achieve outside the hospital, as others have also observed [12,13]. Dietary counseling is difficult because of great differences in the analytical methods regarding content of oxalic acid in various foods. It is important to reduce the fat content in the diet with the addition of medium-chain triglycerides and to supply oral calcium and magnesium salts in large amounts. Recommended are also oral application of citrate, resin exchange, and aluminium hydroxide [14]. As in all patients with kidney stones a large urine volume to avoid a supersaturated urine is of primary importance.

Good results were recently reported with an organic marine hydrocolloid charged with calcium (Ox-absorb), a potent binding substance for oxalate [15]. Because of gastrointestinal side-effects we were not able to treat our patient over a longer period in this way.

Another problem in a patient with global malabsorption is the correct dosage of immunosuppressive drugs. As the absorption and bioavailability of oral cyclosporin in a malabsorption syndrome is unpredictable, cyclosporin has to be administered intravenously with careful monitoring of serum concentrations [7]. In order to achieve immunosuppression with oral medication our patient was put on prednisone and azathioprine because cyclosporin administered orally was poorly absorbed. With a small dosage of $7.5 \mathrm{mg}$ prednisone and $150 \mathrm{mg}$ azathioprine the renal function is normal and no sign of rejection has occurred over the years. In the early phase of transplantation oxalate deposition in the new kidney has to be prevented. Therefore intensive haemodialysis is mandatory, should oliguria occur. In this way serum oxalate levels can be lowered and damage to the kidney transplant avoided. More extensive experience with transplantation has been reported in patients with primary oxalosis $[9,10]$. Good results have been achieved when the patients had a period of intensive dialyses before transplantation. In order to avoid further oxalate accumulation, forced diuresis after transplantation and early haemodialysis is recommended, whenever the cadaver kidney shows a reduced function. We think that the same procedure can be applied for patients with secondary hyperoxaluria. Our good experience with this patient should encourage others to consider kidney transplantation in patients with end-stage renal failure due to enteric hyperoxaluria.

\section{References}

1. Barilla DE, Notz C, Kennedy D, Pak CYC. Renal oxalate excretion following oral oxalate loads in patients with ileal 
disease and with renal and absorptive hypercalciurias: effect of calcium and magnesium. Am J Med 1978; 64: 579-585

2. Chadwick VS, Modha K, Dowling RH. Mechanism for hyperoxaluria in patients with ileal dysfunction. $N$ Engl J Med 1973; 289: $172-176$

3. Earnest DL, Johnson G, Williams HE, Admirand WH. Hyperoxaluria in patients with ileal resection: an abnormality in dietary oxalate absorption. Gastroenterology 1974; 66: 1114-1122

4. Canos HJ, Hogg GA, Jeffery JR. Oxalate nephropathy due to gastrointestinal disorders. Can Med Assoc J 1981; 124: 729-733

5. Das S, Joseph B, Dick AL. Renal failure owing to oxalate nephrosis after jejunoileal bypass. J Urol 1979; 121: 506-509

6. Gelbart DR, Brewer LL, Fajardo LF, Weinstein AB. Oxalosis and chronic renal failure after intestinal bypass. Arch Intern Med 1977; 137: 239-243

7. Roberts RA, Sketris IS, MacDonald AS, Belitsky P. Renal transplantation in secondary oxalosis. Transplantation 1988; 45: $985-986$

8. Morgan JM, Hartley MW, Miller AC, Diethelm AG. Successful renal transplantation in hyperoxaluria. Arch Surg 1974; 109 $430-433$
9. Scheinman JI, Najarian JS, Mauer SM. Successful strategies for renal transplantation in primary oxalosis. Kidney Int 1984; 25: 804-811

10. Whelchel JD, Alison DV, Luke RG, Curtis J, Diethelm AG. Successful renal transplantation in hyperoxaluria. Transplantation 1983; 35: 161-164

11. McDonald GB, Earnest DL, Admirand WH. Hyperoxaluria correlates with fat malabsorption in patients with sprue. Gut 1977; 18: 561-566

12. Earnest DL. Perspectives on incidence, etiology and treatment of enteric hyperoxaluria. Am J Clin Nutr 1977; 30: 72-75

13. Andersson H, Filipsson S, Hulten L. Urinary oxalate excretion related to ileocolic surgery in patients with Crohn's disease. Scand J Gastroenterol 1978; 13: 465-469

14. Laker MF, Hofmann AF. Effective therapy of enteric hyperoxaluria: In vitro binding of oxalate by anion-exchange resins and aluminium hydroxide. J Pharm Sci 1981; 70: 1065-1067

15. Lindsjö M, Fellström B, Ljunghall $S$, Wikström B, Danielson BG. Treatment of enteric hyperoxaluria with calcium-containing organic marine hydrocolloid. Lancet 1989; 2: 701-704 